\title{
Analysis of Expressed Sequence Tags from the Fungal Banana Pathogen Mycosphaerella fijiensis
}

\author{
Yangrae Cho ${ }^{1}$, Shaobin $\mathrm{Hou}^{2}$, and Shaobin Zhong ${ }^{*}, 1,3$ \\ ${ }^{I}$ Department of Plant and Environmental Protection Sciences, University of Hawaii at Manoa, 3190 Maile Way, \\ Honolulu, HI 96822, USA \\ ${ }^{2}$ Center for Genomics, Proteomics and Bioinformatics Research Initiative, University of Hawaii at Manoa, Honolulu, HI \\ 96822, USA \\ ${ }^{3}$ Department of Plant Pathology, North Dakota State University, 306 Walster Hall, Fargo, ND 58105, USA
}

\begin{abstract}
Mycosphaerella fijiensis is a fungal pathogen causing black leaf streak disease in banana plants. In order to develop our understanding of the molecular mechanisms of host infection by $M$. fijiensis, we initiated a first step towards large-scale gene discovery through the generation and analysis of expressed sequence tags (ESTs). Three cDNA libraries representing different culture conditions were constructed. A subset of clones was sequenced at the 5' end and a total of 3,771 ESTs were generated. These ESTs were clustered into a set of 1,945 unique sequences. BLASTX analysis indicated that 410 of the unisequences showed homology to genes with known function, including those related to pathogenicity and virulence. Meanwhile, $66 \%$ and $89 \%$ of the ESTs matched to the predicted transcripts and genome sequences of $M$. $f i$ jiensis, respectively. The diversity of the EST collection developed in this study will facilitate genome annotation as well as identification and characterization of genes involved in host infection and fungal development through a comparative and functional genomics approach.
\end{abstract}

\section{INTRODUCTION}

Mycosphaerella fijiensis causes black leaf streak, commonly known as black Sigatoka and the most destructive fungal disease of banana worldwide. It can affect both old leaves and metabolically active young leaves, cause yield losses up to $50 \%$ or more, and incur serious export problem due to premature fruit ripening $[1,2]$. The disease was first reported in the Sigatoka Valley of Fiji in 1963 and subsequently detected throughout the Pacific and Southeast Asia. It was later identified at Honduras in 1972, Zambia in 1973, and throughout Latin American, African, and Australian banana growing regions by 2000 [3-5].

Disease management is one of the most expensive costs faced by banana growers in the high-rainfall tropics and subtropics, where bananas are of great economic and nutritional importance. Fungicides have been extensively utilized in commercial plantations to manage black Sigatoka. After many years of fungicide-dependent disease control on largescale farms, however, $M$. fijiensis strains tolerant or resistant to diverse fungicides have appeared [6-8]. These resistant strains have created the need for more frequent fungicide applications. In some areas up to 60 spray applications may be needed to control the disease during a 9-month growing season. The systematic application of fungicides raises concern about their impact on the environment and human health [9-12]. Cultural practices, such as the removal of affected leaves, adequate spacing of plants, and efficient

*Address correspondence to this author at the Department of Plant Pathology, North Dakota State University, 306 Walster Hall, Fargo, ND 58105, USA; Tel: 701-231-7427; Fax: 701-231-7851;

E-mail: shaobin.zhong@ndsu.edu drainage within plantations, have played an important role in removing or reducing optimum conditions for disease development. However, these measures are relatively expensive and insufficient to control the disease without fungicides.

Commercial banana cultivars, the major hosts of M. fijiensis, are hybrids of two wild species, Musa acuminata (A genome) and M. balbisiana (B genome). These cultivars have evolved largely via asexual propagation, resulting in limited genetic variation and an increased susceptibility to pests and diseases [13]. Development of disease-resistant plants from commercial cultivars is difficult through traditional breeding methods because they are mostly polyploid hybrids and sterile $[14,15]$. Nevertheless, great efforts have been made in the past decades to develop new banana cultivars resistant to black Sigatoka by introducing resistance genes from wild diploid bananas $[16,17]$. Some of the first high-yielding, diseaseresistant hybrids are available for wide-scale testing and distribution to farmers [18]. However, due to the genetic variability of the pathogen, some resistant banana accessions have become susceptible to $M$. fijiensis isolates in certain regions [19]. Although there have been extensive studies on the genetic diversity of $M$. fijiensis using molecular markers, little is known about the molecular mechanism of the host-pathogen interaction in this pathosystem.

In the past several years, EST analyses have been conducted for many filamentous fungi, including Fusarium graminearum [20], Heterobasidion annosum [21], Magnaporthe grisea [22], Mycosphaerella graminicola [23], Neurospora crassa [24], and Ustilago maydis [25]. In conjunction with fungal genome databases, specific EST databases have appeared and enabled researchers to comprehensively analyze ESTs in order to identify putative pathogenic- 
ity and virulence genes by comparative genomics approaches $[20,23]$. However, analysis of large scale ESTs has not been reported for $M$. fijiensis. The objective of this project was to discover genes through EST analysis of three cDNA libraries from $M$. fijiensis growing under three different culture conditions in order to accomplish our long-term goal to identify and characterize the genes associated with pathogenicity, fungicide resistance, and the life cycle of $M$. fijiensis. In this report we present an analysis of the ESTs from three cDNA libraries and these ESTs will be useful for the whole genome annotation as well as for the understanding of the genetic and molecular interactions between $M$. fijiensis and its banana host.

\section{MATERIAL AND METHODS}

\section{Fungal Isolates and Growth Conditions}

M. fijiensis isolates were obtained from perithecia using the method described by Stover [26]. Briefly, banana leaves infected by $M$. fijiensis were collected in the field and incubated in plastic bags with moist paper towels for 24 hours. Infected leaf tissue was cut into $10 \mathrm{~cm}^{2}$ pieces and stapled to filter papers. The filter papers were wetted, stuck beneath the lids of Petri dishes containing 7.5\% water agar, and incubated 6-12 h until ascopsores were discharged. Individual ascospores were transferred to Potato Dextrose Agar (PDA) using a fine scalpel. Typical pink-colored colonies formed after incubation for 2-3 weeks at an ambient temperature $\left(22-25^{\circ} \mathrm{C}\right)$ and continuous, cool-white fluorescent light (1200-1250 lux). Identification of the M. fijiensis isolates was confirmed by PCR using M. fijiensis-specific primers [27].

Two M. fijiensis isolates (MF5-Hilo and MF11-Hilo) were used to construct cDNA libraries. Mycelia for construction of the first cDNA library (PA) were obtained from MF11-Hilo grown on PDA for 4 weeks under continuous, cool-white, fluorescent light (1200-1250 lux). For construction of the second cDNA library (FL), a colony of MF5-Hilo on PDA was transferred into a sterile mortar containing $5 \mathrm{ml}$ of Fries liquid medium [5.0 g ammonium tartrate, $1.0 \mathrm{~g}$ ammonium nitrate, $0.5 \mathrm{~g}$ magnesium sulfate, $1.3 \mathrm{~g}$ potassium phosphate (dibasic), $2.6 \mathrm{~g}$ potassium phosphate (monobasic), $30.0 \mathrm{~g}$ sucrose, $1.0 \mathrm{~g}$ yeast extract, dissolved in $1000 \mathrm{ml}$ water] and ground with a pestle. The ground mycelia were used to inoculate $100 \mathrm{ml}$ of Fries liquid medium in a $250 \mathrm{ml}$ flask, which was then incubated at $26^{\circ} \mathrm{C}$ on a shaker at $125 \mathrm{rpm}$. After 4 days, the mycelia were harvested by filteration through two-layers of MiraCloth (CalBiochem, La Jolla, $\mathrm{CA}$ ), washed once with distilled water, then snap-frozen in liquid nitrogen before storing at $-80^{\circ} \mathrm{C}$. Mycelia for construction of the third cDNA library $(\mathrm{HX})$ were prepared as described for cDNA library FL, but $30 \mathrm{ml}$ of banana leaf extract was added to the 4-day-old mycelium, then cultured for an additional 24 hours. The banana leaf extract was prepared by homogenizing $30 \mathrm{~g}$ of young banana leaves in 50 $\mathrm{ml}$ sterile water, filtering it through four layers of cheesecloth, then filter-sterilizing it using a $0.22 \mu \mathrm{m}$ filter.

\section{RNA Isolation and cDNA Library Construction}

Total RNA was isolated from fungal mycelia with the RNeasy Plant Mini Kit (Qiagen, Valencia, CA) according to the manufacturer's protocol. All three cDNA libraries were constructed using the SMART cDNA Library Construction Kit (DB-Bioscience-ClonTech, Palo Alto, CA) and the Gateway (Invitrogen, Carlsbad, CA) cloning system with modifications from manufacturers' protocols (Fig. 1). For first-strand cDNA synthesis, 0.5 to $1.0 \mu \mathrm{g}$ of total RNA was mixed with $2 \mu 1$ of each anchored attB2-oligo-dT primer (10 $\mathrm{mM}$ ) (GGGGACCACTTTGTACAAGAAAGCTGGGTTTT TTTTTTTTTTTTTTTTVN) and attB1-Switch primer (10 mM) (GGGGACAAGTTTGTACAAAAAAGCAGGCTrGr $\mathrm{GrG}$ ), where $\mathrm{rG}$ represents ribonucleotide. The mixture was incubated at $68^{\circ} \mathrm{C}$ for 2 minutes, then cooled on ice for 2 minutes before adding $4 \mu 1$ of $5 \times$ buffer, $2 \mu 1$ of DTT $(100 \mathrm{mM})$, $1 \mu \mathrm{l}$ of dNTPs $(10 \mathrm{mM})$, and $1 \mu \mathrm{l}$ of Superscript III reverse transcriptase ( 5 units $/ \mu 1$ ). Water was added to a final volume of $20 \mu \mathrm{l}$. The reverse transcription reaction was incubated for 1 hour in a thermocycler at $50^{\circ} \mathrm{C}$. Two microliters of the firststrand cDNA was used as a template in a $100 \mu \mathrm{PCR}$ reaction containing 1x Advantage 2 PCR buffer, $2.0 \mathrm{U}$ of Advantage 2 Polymerase Mix (Clontech, CA), $0.25 \mu \mathrm{M}$ each of primers attB1 (GGGGACAAGTTTGTACAAAAAAGCAGGCT) and attB2 (GGGGACCACTTTGTACAAGAAAGCTGGGT), and $2 \mu \mathrm{l}$ of dNTP $(10 \mathrm{mM})$. PCR was performed at $94^{\circ} \mathrm{C}$ for 2 minutes for the initial denaturation, followed by $\sim 18$ to 22 cycles at $94^{\circ} \mathrm{C}$ for 20 seconds, $61^{\circ} \mathrm{C}$ for 30 seconds, and $72^{\circ} \mathrm{C}$ for $5 \mathrm{~min}$. PCR products were visualized on $1 \%$ agarose gels. The amplified cDNA products were processed on a Chroma spin column (DB-Bioscience-ClonTech, Palo Alto, CA) to remove fragments smaller than 500 base pairs. The purified cDNA was then incorporated into the plasmid pDONR221 by recombination using $\mathrm{BP}$ clonase as described in the manufacturer's protocol (Invitrogen, Carlsbad, CA). The plasmids were transformed into DH10B E. coli strain.

\section{DNA Sequencing and Data Analysis}

The cDNA libraries were spread on Luria-Bertani (LB) agar plates containing $50 \mu \mathrm{g} / \mathrm{ml}$ kanamycin. Individual colonies from each of the three libraries were transferred into 96well microtiter plates with LB containing kanamycin and $18 \%$ glycerol. The plates from each library were sent to the Center for Genomics, Proteomics and Bioinformatics Research Initiative, University of Hawaii at Manoa, for sequencing on an ABI Model 377 DNA sequencer. Sequencing reactions were performed with standard Big Dye (Applied Biosystems, Foster City, CA) protocols and sequences were determined only at the $5^{\prime}$ end of each clone.

Raw sequence chromatogram trace files were processed by the program Phred (http://www.phrap.org) using its trimming options in order to remove low quality ends [28]. All automated sequences were manually examined in order to ensure high quality; incorrectly called bases were corrected and unassigned bases were correctly identified. Cross match in the Phred-Phrap was used to automatically remove vector sequences with the aid of a custom database containing vectors and adapters used for cloning in the libraries. The program was also used to assemble the resulting EST sequences into overlapping contigs and singlets. Redundancy was calculated with the formula [(total number of sequences - total number of unisequences) / (total number of sequences)]. All ESTs have been submitted to the NCBI GenBank dbEST (accession numbers FB531204-FB535042). 
PolyA mRNA
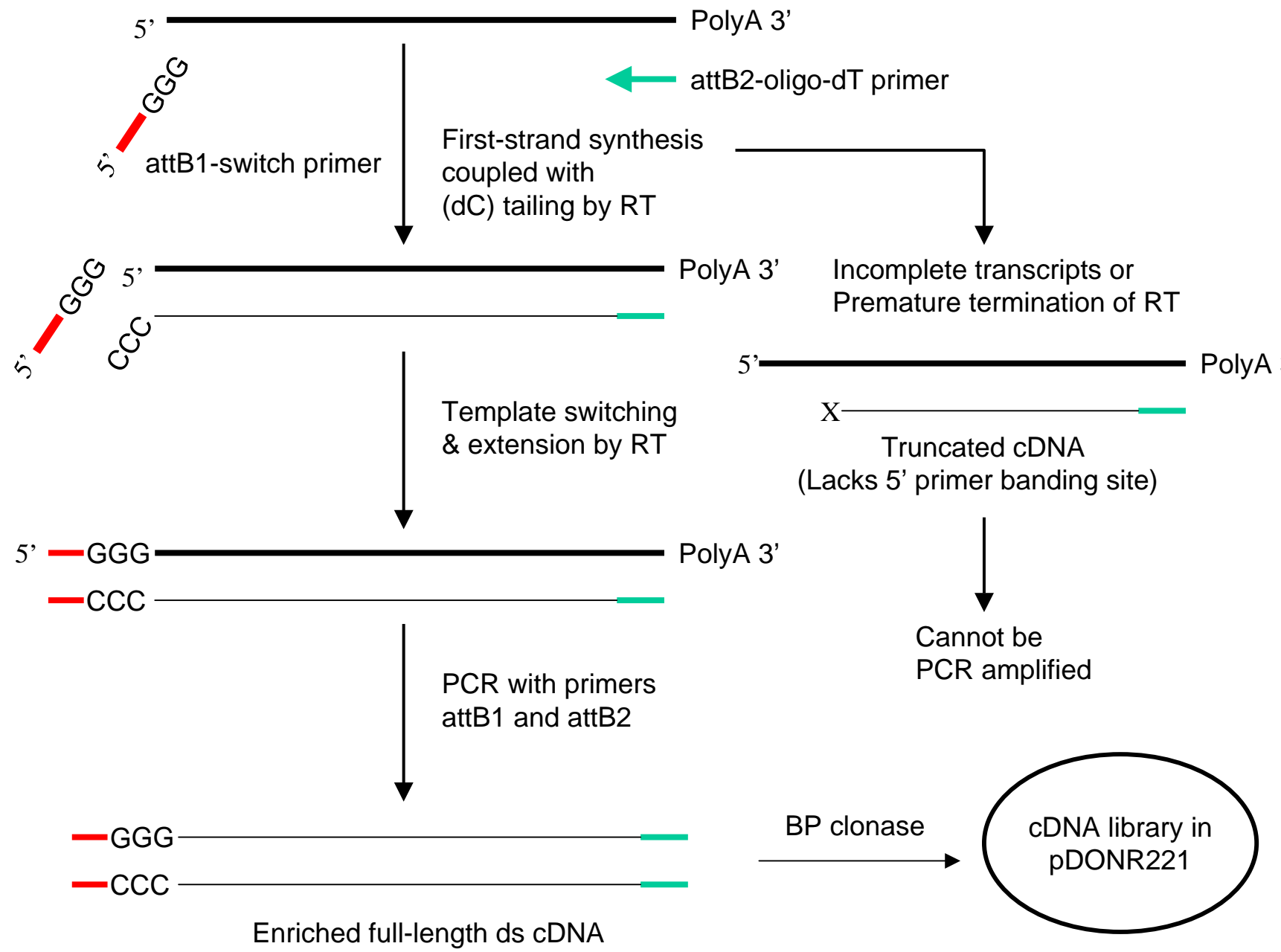

Fig. (1). Schematic diagram depicting how cDNA libraries were constructed, starting from mRNA in the total RNA in order to enrich fulllength cDNA clones.

BLAST searches were conducted with stand-alone BLAST programs available from ftp://ftp.ncbi.nih.gov/blast/executables/. ESTs were searched against the non-redundant NCBI database for homologs using the Blastx algorithms [29]. Sequences showing significant similarity (E-value $<1 \mathrm{e}-05$ ) to characterized proteins were categorized based on the MIPS scheme outlined in the MIPS database [30]. Comments from the header section of the NR records were the primary sources of information used to assign putative functions to the $M$. fijiensis unisequences. The unisequences were also queried against the predicted protein sequences of 18 sequenced fungal genomes using BLASTX. The predicted transcript sequences were downloaded on June 1, 2008 from two websites: the Fungal Genome Initiative at the Broad Institute (http://www.broad. mit.edu/annotation/fungi/fgi/) and Eukaryotic Genomics at the DOE Joint Genome Institute (JGI) (http:/genome.jgi-psf.org/ euk_cur1.html). For each genome analyzed, we calculated the number and percentage of $M$. fijiensis unisequences that had a homolog with E-values of $<1 \mathrm{e}-05,<1 \mathrm{e}-40$, and $<1 \mathrm{e}-100$. Further more, we compared the ESTs to the draft assembly of whole genome sequence reads of $M$. fijiensis, which included 382 scaffolds and 10,313 predicted transcripts. First, the 3,771 ESTs were queried against the database of the predicted transcripts using BLASTN. Queried sequences that had a mini- mum $90 \%$ identity over at least 50 base pairs of alignment to a predicted transcript sequence were considered significant (Evalue $<1 \mathrm{e}-5$ ) and exported to an Excel database for further analysis. Sequences that did not have hits were used with the BLASTN algorithm to query the database of 382 scaffolds representing the draft sequence of the whole genome. The results of these BLAST searches were used to classify the origin of each EST and evaluate its usefulness for gene prediction. All scripts used for the above analyses were kindly provided by Dr. Zheng Jin Tu and run in the Unix system of the Supercomputer Institute of the University of Minnesota, St. Paul, MN.

\section{RESULTS}

\section{Construction and Characteristics of cDNA Libraries}

We constructed separate cDNA libraries using the total RNA isolated from fungal tissues grown under three culture conditions, i.e., on the PDA media (PA library), Fries liquid media (FL library), and Fries liquid media supplemented by host plant extract (HX library). Our primary goal was to understand the similarities and differences in gene expression patterns under these three different growth conditions. The secondary goal was to identify the infection related genes 
among abundantly expressed ones by comparing EST collections to public databases.

Whole fungal tissues grown on PDA were used as RNA sources in order to identify genes expressed during growth on a hard agar surface. Meanwhile, mycelia grown in the Fries medium as well as in media supplemented by host plant extract were used as RNA sources in order to discover genes expressed under similar environmental conditions during host plant infection. Titers of $8.6 \times 10^{6}, 5.2 \times 10^{6}$, and $3.5 \times 10^{6}$ colonies $/ \mathrm{ml}$ were obtained from libraries PA, FL, and $\mathrm{HX}$, respectively. The average titer for the three libraries was $5.8 \times 10^{6}$ colonies $/ \mathrm{ml}$. Examination of sixty randomly picked clones from each library by PCR with the primers attB1 and attB2 showed that over $98 \%$ of the clones had inserts ranging in size from $0.3 \mathrm{~kb}$ to $3.5 \mathrm{~kb}$. Average insert size was $1.2 \mathrm{~kb}$ for PA, $1.3 \mathrm{~kb}$ for FL and $1.1 \mathrm{~kb}$ for $\mathrm{HX}$.

\section{Distribution of ESTs to Clusters, Contigs, and Singletons}

A subset $(1,344,1,344$, and 1,152) of cDNA clones from the three independent cDNA libraries (PA, FL, and HX) were sequenced at the $5^{\prime}$ ends and 1,310,1,322, and 1,139 individual ESTs were generated, respectively. The length of the EST sequences ranged from 214 to $998 \mathrm{bp}$ with an average of $748 \mathrm{bp}$. The resulting 3,771 ESTs were assembled into 562 contigs and 1,383 singletons generating a total of 1,945 unique sequences. The rate of redundancy for all three cDNA libraries combined was $45 \%$, while the redundancy for each library ranged from 31 to $44 \%$ (Table 1). More than one contig may correspond to the same transcript, and some degree of redundancy may not be detected. Because all three libraries were constructed directionally and the sequences were determined only in one direction, from the 5' side, the undetected redundancy theoretically originated from the incomplete synthesis of the first strand. The relatively high redundancy rate in all three libraries suggests that EST sequencing efforts passed the cost efficient stage with these libraries to find novel sequences although further sequencing of the library would yield more of them.

Table 1. Summary of EST Collections from Mycosphaerella fijiensis Grown Under Three Different Culture Conditions

\begin{tabular}{|c|c|c|c|}
\hline Library & Total Sequences & Unisequences & Redundancy \\
\hline \hline PA & 1310 & 901 & $31 \%$ \\
\hline FL & 1322 & 797 & $40 \%$ \\
\hline HX & 1139 & 643 & $44 \%$ \\
\hline Combined & 3771 & 1945 & $45 \%$ \\
\hline
\end{tabular}

Nonetheless, about 95\% (1841/1945) of the total unisequences were either singletons or contigs formed by less than five overlapping ESTs. Only 5\% (104/1945) of unisequences were contigs generated by 5 or more overlapping ESTs, suggesting that the redundancy was mainly caused by a few highly expressed genes. As we determine the nucleotide sequences of additional cDNA clones, we will find more ESTs belong to the already identified sequences, especially these highly expressed genes. Subtraction by those small numbers of highly expressed genes would be helpful to in- crease the gene discovery rate $[21,31]$. Alternatively, the suppression subtractive hybridization ( $\mathrm{SSH}$ ) method could be utilized to create the infection-specific library containing a mixture of both plant and fungal genes that are responsible for host and microbe interaction with an unbiased and equal representation [32].

Comparisons of the unisequences between and among the three libraries discovered only 99 contigs consisting of ESTs derived from all three libraries. There were 105 contigs overlapping between libraries PA and FL; 92 between libraries FL and $\mathrm{HX}$ and 81 between libraries PA and HX. A large number of unisequences was specific to each library, accounting for 68,63 and $58 \%$ of the total unisequences generated from libraries PA, FL and HX, respectively (Fig. 2). Although EST sequencing from each library was only a little over 1000, they were likely to represent expression profiles because all libraries were constructed without subtraction or normalization procedures. The high numbers of library-specific ESTs suggest different fungal reactions to the three different environmental conditions. However, the differences among the three libraries may have been partially due to other factors, such as the difference between the two isolates (MF-11 and MF-5), the use of 4-week-old mycelia for the PA library and 4- to 5-day-old mycelia for the FL and HX libraries, and two different culture media. Alternatively, the EST collection was not deep enough from each library to detect transcripts that are expressed at a low level. Consistent to this hypothesis, numbers of genes in each MIP category is similar with limited overlaps among three libraries (See below).

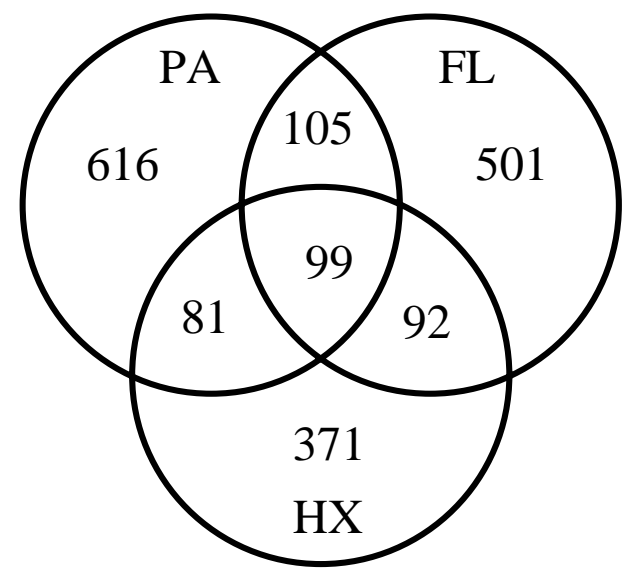

Fig. (2). Distribution of unisequences among three libraries. The numbers in the overlapping segments indicate the number of unisequences composed of ESTs derived from the designated libraries.

\section{Highly Expressed Sequences}

To examine the highly expressed sequences, we analyzed 45 contigs consisting of 10 or more ESTs (Table 2). BLASTX analysis showed that fourteen contigs had no matching sequences in the NCBI database when a significant threshold of E-value $<1 \mathrm{e}-05$ was used as a cutoff. Among the 31 contigs with homologs, 10 were in the unknown functional category and seven were ribosomal proteins. The other 14 contigs showed similarities to genes with known functions. These known products include: glucose repressible gene protein, intracellular protease/amidase, opsin or opsinlike protein, superoxide dismutase, cation-transport related 
Table 2. Top 40 Abundantly Expressed Genes Measured by EST Redundancy

\begin{tabular}{|c|c|c|c|c|c|c|c|c|}
\hline MF_Contig & $\mathbf{T}$ & PA & FL & $\mathbf{H X}$ & Gene_Description & Organism & Accession_No & E-Value \\
\hline MF_contig518 & 10 & 1 & 3 & 6 & ribosomal protein & Gibberella zeae & XP_381414 & $1.20 \mathrm{E}-34$ \\
\hline MF_contig519 & 10 & 2 & 3 & 5 & glucose repressible gene protein & Magnaporthe grisea & $\operatorname{mg}[0624]$ & $3.58 \mathrm{E}-22$ \\
\hline MF_contig520 & 10 & 4 & 2 & 4 & - & - & - & - \\
\hline MF_contig521 & 10 & 4 & 4 & 2 & ribosomal protein & Aspergillus fumigatus & XP_755254 & $6.16 \mathrm{E}-43$ \\
\hline MF_contig522 & 10 & 9 & 1 & 0 & hypothetical protein & Aspergillus fumigatus & XP_746739 & $1.88 \mathrm{E}-56$ \\
\hline MF_contig523 & 10 & 1 & 4 & 5 & ribosomal protein & Chaetomium globosum & EAQ85719 & $3.03 \mathrm{E}-112$ \\
\hline MF_contig524 & 10 & 9 & 1 & 0 & - & - & - & - \\
\hline MF_contig525 & 11 & 6 & 2 & 3 & cation transport-related protein & Cryptococcus neoformans & AAW42114 & $1.66 \mathrm{E}-21$ \\
\hline MF_contig526 & 11 & 1 & 2 & 8 & myo-inositol-phosphate synthase & Aspergillus fumigatus & XP_749237 & $6.45 \mathrm{E}-118$ \\
\hline MF_contig527 & 11 & 6 & 4 & 1 & - & - & - & - \\
\hline MF_contig528 & 11 & 2 & 4 & 5 & ribosomal protein & Aspergillus fumigatus & XP_755074 & $1.63 \mathrm{E}-61$ \\
\hline MF_contig529 & 12 & 1 & 6 & 5 & ribosomal protein & Magnaporthe grisea & AAW69354 & $2.61 \mathrm{E}-76$ \\
\hline MF_contig530 & 12 & 9 & 1 & 2 & opsin & Leptosphaeria maculans & AAG01180 & $1.44 \mathrm{E}-82$ \\
\hline MF_contig531 & 12 & 2 & 7 & 3 & unnamed protein product & Aspergillus oryzae & BAE59062 & $3.11 \mathrm{E}-47$ \\
\hline MF_contig532 & 12 & 6 & 2 & 4 & histone $\mathrm{H} 4$ & Aspergillus nidulans & XP_658338 & $1.37 \mathrm{E}-34$ \\
\hline MF_contig533 & 12 & 4 & 6 & 2 & translation elongation factor & Candida albicans & XP_711870 & 0 \\
\hline MF_contig534 & 13 & 8 & 4 & 1 & - & - & - & - \\
\hline MF_contig535 & 13 & 0 & 9 & 4 & unknown & Magnaporthe grisea & $\operatorname{mg}[0708]$ & $4.98 \mathrm{E}-28$ \\
\hline MF_contig536 & 13 & 2 & 6 & 5 & ribosomal subunit & Aspergillus fumigatus & XP_754922 & $2.13 \mathrm{E}-131$ \\
\hline MF_contig537 & 14 & 7 & 2 & 5 & ribosomal protein & Aspergillus fumigatus & XP_751010 & 4.07E-51 \\
\hline MF_contig538 & 14 & 1 & 9 & 4 & zinc metalloproteinase & Aspergillus fumigatus & XP_752634 & $1.38 \mathrm{E}-44$ \\
\hline MF_contig539 & 15 & 12 & 0 & 3 & hypothetical protein & Aspergillus nidulans & XP_660742 & $5.60 \mathrm{E}-32$ \\
\hline MF_contig540 & 16 & 0 & 4 & 12 & cation transport-related protein & Cryptococcus neoformans & AAW42114 & $1.52 \mathrm{E}-21$ \\
\hline MF_contig541 & 16 & 0 & 7 & 9 & - & - & - & - \\
\hline MF_contig542 & 16 & 6 & 4 & 6 & Superoxide dismutase & Yersinia enterocolitica & CAA65596 & 7.64E-70 \\
\hline MF_contig543 & 16 & 3 & 9 & 4 & hypothetical protein & Gibberella zeae & XP_390148 & $1.42 \mathrm{E}-15$ \\
\hline MF_contig544 & 18 & 4 & 8 & 6 & hypothetical protein & Gibberella zeae & XP_388414 & 7.69E-28 \\
\hline MF_contig545 & 19 & 4 & 8 & 7 & hypothetical protein & Aspergillus nidulans & XP_661903 & $4.50 \mathrm{E}-58$ \\
\hline MF_contig546 & 20 & 3 & 10 & 7 & glucose repressible gene protein & Magnaporthe grisea & $\operatorname{mg}[0624]$ & $1.51 \mathrm{E}-23$ \\
\hline MF_contig547 & 21 & 0 & 12 & 9 & - & - & - & - \\
\hline MF_contig548 & 21 & 13 & 5 & 3 & - & - & - & - \\
\hline MF_contig549 & 22 & 6 & 7 & 9 & - & - & - & - \\
\hline MF_contig550 & 23 & 13 & 8 & 2 & - & - & - & - \\
\hline MF_contig551 & 27 & 22 & 4 & 1 & - & - & - & - \\
\hline MF_contig552 & 28 & 1 & 15 & 12 & intracellular protease/amidase & Gibberella zeae & XP_389155 & 4.31E-61 \\
\hline MF_contig553 & 28 & 1 & 9 & 18 & unknown & Cladosporium fulvum & Cf8667490 & $3.98 \mathrm{E}-10$ \\
\hline MF_contig554 & 31 & 26 & 2 & 3 & hypothetical protein & Neurospora crassa & T49762 & $3.85 \mathrm{E}-24$ \\
\hline MF_contig555 & 33 & 30 & 3 & 0 & opsin-like protein & Gibberella fujikuroi & CAD97459 & $1.72 \mathrm{E}-83$ \\
\hline MF_contig556 & 36 & 24 & 2 & 10 & - & - & - & - \\
\hline MF_contig557 & 36 & 8 & 12 & 16 & - & - & - & - \\
\hline MF_contig558 & 38 & 14 & 7 & 17 & histone $\mathrm{H} 3$ & Chaetomium globosum & AAT74576 & $2.71 \mathrm{E}-68$ \\
\hline MF_contig559 & 59 & 3 & 34 & 22 & - & - & - & - \\
\hline MF_contig560 & 64 & 0 & 36 & 28 & glucose repressible gene protein & Magnaporthe grisea & $\operatorname{mg}[0624]$ & $1.23 \mathrm{E}-24$ \\
\hline MF_contig561 & 74 & 10 & 20 & 44 & - & - & - & - \\
\hline MF_contig562 & 170 & 33 & 84 & 53 & unnamed protein product & Aspergillus oryzae & BAE59652 & $6.47 \mathrm{E}-27$ \\
\hline
\end{tabular}


protein, zinc metalloproteinase, translation-elongation factor, myo-inositol-phosphate synthase, and histone $\mathrm{H} 4$ protein. Comparison of the three libraries indicates that the gene expression is more similar between FL and HX than between the other two pairs. For example, library PA has more expression of opsin or opsin-like proteins than FL and HX, but glucose repressible gene is highly expressed in FL and HX. This is likely due to the similar growth conditions in liquid media for FL and HX tissues. However, we do not exclude another possibility that the discrepancies reflect the differences between the two strains, Hilo-11 and Hilo-5.

\section{Functional Annotation of ESTs}

In order to determine the putative function of each EST in all three libraries, multi-dimensional sequence analysis was performed based on a series of BLAST searches [29]. BLASTX comparisons to the Genbank NR database enabled us to classify 2,259 ESTs $(\sim 60 \%)$ based on sequence similarities to genes with known and unknown functions in the databases. The remaining non-hit ESTs were further analyzed with TBLASTX against over 50,000 ESTs originated from fifteen pathogenic fungi and oomycete species, and three nonpathogenic fungi present in the COGEME phytopathogen EST database (http://cogeme.ex.ac.uk/) [33]. This approach led us to identify 445 more ESTs with similarities to functionally unclassified genes. Combining BLASTX and TBLASTX analyses indicated that approximately $72 \%$ of the ESTs from the three libraries had similar sequences in the public databases.
Based upon the MIPS classification system (http://mips. gsf.de/), we annotated each EST exhibiting the most significant BLASTX hit according to a functional category. The proportions of functional categories expressed as a percentage of the total collection for each of the three individual EST libraries are displayed in Table 3. We were especially interested in the ESTs derived from the FL library as many fungal pathogenesis genes have previously been suggested to be expressed under nitrogen-limiting, or starvation conditions [34]. None of the specific functional categories, except slightly higher numbers of genes with unknown functions, showed noticeable differences in the FL library compared to the others. On the other hand, ESTs derived from HX library showed slightly higher numbers of genes expressed in three categories; energy, cellular transport, and biogenesis of cellular components. These are thought to be important components for nutrient uptake and nutrient metabolism, but not for infection-related functions (see next section). In general, the percentage of expressed genes in each library was similar, except for the category of response to the cellular environment. The PA library had a higher percentage of genes responding to the cellular environment.

\section{ESTs Predicted to be Involved in Pathogenicity}

Using similarity as an indicator of functions, we identified 50 genes putatively involved in pathogenicity (Table 4). These genes encode proteins for infection structures, toxin synthesis and efflux, detoxification, nutrient and metabolite

Table 3. Functional Classification of ESTs for Each Library and the Total Collection Based on The Munich Information Center for Protein Sequences (MIPS) Scheme

\begin{tabular}{|c|c|c|c|c|c|}
\hline 01 & Metabolism & $59(7.3 \%)$ & $78(9.6 \%)$ & $56(8.0 \%)$ & $193(8.3 \%)$ \\
\hline 10 & Cell Cycle and DNA Processing & $2(0.2 \%)$ & $3(0.4 \%)$ & $1(0.1 \%)$ & $6(0.3 \%)$ \\
\hline 11 & Transcription & $12(1.5 \%)$ & $1(0.1 \%)$ & $8(1.1 \%)$ & $21(0.9 \%)$ \\
\hline 14 & Protein Fate (folding, modification, destination) & $11(1.4 \%)$ & $5(0.6 \%)$ & $12(1.7 \%)$ & $29(1.2 \%)$ \\
\hline 16 & Protein with Binding Function & $13(1.6 \%)$ & $12(1.5 \%)$ & $4(0.6 \%)$ & $29(1.2 \%)$ \\
\hline 18 & Protein Activity Regulation & $3(0.4 \%)$ & $7(0.9 \%)$ & $9(1.3 \%)$ & $19(0.8 \%)$ \\
\hline 20 & Cellular Transport, Transport Facilitation and Transport Routes & $25(3.1 \%)$ & $17(2.1 \%)$ & $28(4.0 \%)$ & $70(3.0 \%)$ \\
\hline 36 & Interaction with the Environment (Systemic) & $0(0.0 \%)$ & $0(0.0 \%)$ & $1(0.1 \%)$ & $1(0.0 \%)$ \\
\hline 40 & Cell Fate & $0(0.0 \%)$ & $0(0.0 \%)$ & $3(0.4 \%)$ & $3(0.1 \%)$ \\
\hline 41 & Development (Systemic) & $1(0.1 \%)$ & $1(0.1 \%)$ & $0(0.0 \%)$ & $2(0.1 \%)$ \\
\hline 42 & Biogenesis of Cellular Components & $31(3.8 \%)$ & $20(2.5 \%)$ & $46(6.5 \%)$ & $97(4.2 \%)$ \\
\hline 98 & Classification Not Yet Clear-cut & $7(0.9 \%)$ & $10(1.2 \%)$ & $2(0.3 \%)$ & $19(0.8 \%)$ \\
\hline \multirow[t]{2}{*}{99} & Unknown protein & $507(62.7 \%)$ & $534(65.4 \%)$ & $410(58.3 \%)$ & $1451(62.4 \%)$ \\
\hline & Total & $809(100 \%)$ & $816(100 \%)$ & $703(100 \%)$ & $2327(100 \%)$ \\
\hline
\end{tabular}


Table 4. M. fijiensis Genes that Share Significant Sequence Similarities to Verified Pathogenicity Genes in Other Fungi

\begin{tabular}{|c|c|c|c|c|}
\hline EST & Library & Gene_Description & Accession_No & Evalue \\
\hline \multicolumn{5}{|l|}{ Infection structure } \\
\hline MF56-01_M13F-F02 & $\operatorname{HX}(1)$ & related to hard surface induced protein 3 [Neurospora crassa] & CAE85497 & $4.85 \mathrm{E}-23$ \\
\hline MF11-14_M13F-A11 & $\mathrm{PA}(1)$ & hydrophobic surface binding protein B [Aspergillus oryzae] & BAE53530 & $1.24 \mathrm{E}-09$ \\
\hline \multicolumn{5}{|c|}{ Fungal toxin synthesis and efflux } \\
\hline MF05-14_M13F-B01 & $\mathrm{FL}(1)$ & branched-chain amino acid aminotransferase [Aspergillus fumigatus] & XP_752208 & $1.08 \mathrm{E}-81$ \\
\hline MF11-12_M13F-G01 & $\mathrm{PA}(1)$ & trichothecene efflux pump [Gibberella zeae] & AAM49050 & $1.24 \mathrm{E}-08$ \\
\hline MF56-07_M13F-F10 & $\operatorname{HX}(1)$ & fatty acid elongase (FEN1) [Neurospora crassa] & CAD70918 & 4.17E-69 \\
\hline \multicolumn{5}{|c|}{ Detoxification, drug resistance and metabolite transport } \\
\hline MF05-04_M13F-F10 & $\mathrm{FL}(1)$ & major facilitator superfamily [Leptosphaeria maculans] & AAO49453 & $2.48 \mathrm{E}-105$ \\
\hline MF05-03_M13F-A04 & $\operatorname{FL}(1)$ & neutral amino acid permease [Aspergillus fumigatus] & XP_747312 & $2.45 \mathrm{E}-36$ \\
\hline MF56-08_M13F-A03 & $\mathrm{HX}(1)$ & putative MFS transporter [Gibberella moniliformis] & CAI60779 & $2.19 \mathrm{E}-126$ \\
\hline MF05-10_M13F-C10 & PA(1), FL(1) & related to brefeldin A resistance protein [Neurospora crassa] & CAF06031 & $1.44 \mathrm{E}-75$ \\
\hline MF05-09_M13F-A01 & $\operatorname{FL}(1)$ & related to neomycin resistance protein NEO1 [Neurospora crassa] & CAC18258 & $1.94 \mathrm{E}-62$ \\
\hline MF56-01_M13F-A01 & $\mathrm{HX}(1)$ & sucrose transporter, putative [Aspergillus fumigatus] & EAL91974 & $1.06 \mathrm{E}-54$ \\
\hline MF11-07_M13F-C07 & $\mathrm{PA}(1)$ & transmembrane transporter [Aspergillus fumigatus] & XP_748898 & $2.55 \mathrm{E}-56$ \\
\hline MF05-01_M13F-C05 & $\mathrm{FL}(1)$ & mitochondrial carrier protein [Aspergillus fumigatus] & XP_751597 & $7.65 \mathrm{E}-38$ \\
\hline \multicolumn{5}{|c|}{ Signal cascade components } \\
\hline MF05-02_M13F-C12 & $\operatorname{PA}(1), \mathrm{FL}(1)$ & signal recognition particle protein [Aspergillus fumigatus] & XP_751808 & $1.38 \mathrm{E}-56$ \\
\hline MF11-10_M13F-B09 & $\mathrm{PA}(1)$ & related to serine/threonine-protein kinase [Neurospora crassa] & CAD79666 & $7.35 \mathrm{E}-56$ \\
\hline MF11-10_M13F-E10 & $\mathrm{PA}(3)$ & protein serine/threonine kinase Ran1 [Aspergillus fumigatus] & XP_754566 & $8.99 \mathrm{E}-56$ \\
\hline \multicolumn{5}{|c|}{ Protection agaist oxidative stress } \\
\hline MF11-13_M13F-G12 & $\mathrm{PA}(1)$ & catalase [Gibberella zeae] & AAO34682 & $1.40 \mathrm{E}-20$ \\
\hline MF11-13_M13F-H11 & PA(1), FL(1) & Superoxide dismutase [Haemophilus somnus] & ZP_00132526 & $8.44 \mathrm{E}-26$ \\
\hline MF11-08_M13F-D04 & $\mathrm{PA}(1)$ & $\mathrm{Cu}, \mathrm{Zn}$ superoxide dismutase SOD1 [Aspergillus fumigatus] & XP_753715 & 7.09E-68 \\
\hline MF56-11_M13F-D12 & $\mathrm{HX}(1)$ & cytochrome c oxidase polypeptide V [Aspergillus nidulans] & XP_659920 & $2.38 \mathrm{E}-48$ \\
\hline MF05-02_M13F-D09 & $\mathrm{FL}(4)$ & cytochrome c1 precursor [Neurospora crassa] & CAA28860 & $2.05 \mathrm{E}-93$ \\
\hline MF05-03_M13F-G10 & $\mathrm{FL}(1)$ & cytochrome P450 monooxygenase [Aspergillus fumigatus] & XP_746946 & $9.88 \mathrm{E}-35$ \\
\hline MF11-12_M13F-C12 & $\mathrm{PA}(2)$ & monooxigenase [Aspergillus fumigatus] & XP_751255 & $3.18 \mathrm{E}-80$ \\
\hline MF56-12_M13F-E06 & $\mathrm{HX}(2)$ & cytochrome-c oxidase chain VI precursor [Neurospora crassa] & CAD70919 & $2.75 \mathrm{E}-42$ \\
\hline MF05-08_M13F-H09 & $\mathrm{PA}(3), \mathrm{FL}(3), \mathrm{HX}(6)$ & sodA [Yersinia enterocolitica $]$ & CAA65596 & $2.30 \mathrm{E}-70$ \\
\hline MF11-05_M13F-A03 & $\mathrm{PA}(1)$ & Superoxide dismutase (Mn) [Escherichia coli $]$ & AAN83287 & $1.64 \mathrm{E}-61$ \\
\hline MF56-09_M13F-E03 & $\mathrm{HX}(2)$ & Tyrosinase [Monophenol monooxygenase] & Q92396 & $3.12 \mathrm{E}-22$ \\
\hline MF05-07_M13F-F07 & $\mathrm{FL}(1)$ & tyrosinase precursor [Neurospora crassa] & CAE81941 & $2.26 \mathrm{E}-24$ \\
\hline MF05-08_M13F-A02 & $\mathrm{FL}(3)$ & epoxidase subunit A [Penicillium decumbens] & BAA75924 & $1.23 \mathrm{E}-71$ \\
\hline
\end{tabular}


(Table 4) contd.....

\begin{tabular}{|c|c|c|c|c|}
\hline EST & Library & Gene_Description & Accession_No & Evalue \\
\hline \multicolumn{5}{|l|}{ hydrolytic enzyme } \\
\hline MF11-06_M13F-D03 & $\operatorname{PA}(1)$ & 1,3-beta glucanase [Blumeria graminis] & AAL26905 & $5.66 \mathrm{E}-65$ \\
\hline MF11-07_M13F-D08 & $\mathrm{PA}(1), \mathrm{HX}(1)$ & aspartic proteinase precursor [Botryotinia fuckeliana] & AAR13364 & $5.24 \mathrm{E}-105$ \\
\hline MF56-04_M13F-C06 & $\mathrm{HX}(3)$ & zinc metalloproteinase, putative [Aspergillus fumigatus] & EAL90596 & $5.65 \mathrm{E}-43$ \\
\hline \multicolumn{5}{|c|}{ Avirulence/virulence factors } \\
\hline MF05-14_M13F-B11 & $\mathrm{PA}(2), \mathrm{FL}(1), \mathrm{HX}(2)$ & Avr4 [Cladosporium fulvum] & CAA55403 & $1.80 \mathrm{E}-17$ \\
\hline MF05-07_M13F-C09 & $\mathrm{FL}(2), \operatorname{PA}(2)$ & ecp2 [Cladosporium fulvum] & CAA78401 & $7.22 \mathrm{E}-49$ \\
\hline MF05-11_M13F-B02 & $\operatorname{PA}(2), \mathrm{FL}(2), \mathrm{HX}(2)$ & Protein SnodProt1 precursor [Phaeosphaeria nodorum] & $\mathrm{O} 74238$ & $2.81 \mathrm{E}-37$ \\
\hline MF56-05_M13F-G11 & $\mathrm{PA}(1), \mathrm{HX}(2)$ & pSI-7 protein [Cladosporium fulvum] & CAA74888 & $1.06 \mathrm{E}-92$ \\
\hline MF56-11_M13F-D06 & $\mathrm{PA}(4), \mathrm{FL}(2), \mathrm{HX}(1)$ & virulence related protein Cap20 [Aspergillus fumigatus] & EAL88346 & $2.74 \mathrm{E}-29$ \\
\hline \multicolumn{5}{|l|}{ Miscellaneous } \\
\hline MF05-04_M13F-G02 & $\mathrm{FL}(1)$ & isocitrate lyase [Leptosphaeria maculans] & AAM89498 & $3.25 \mathrm{E}-70$ \\
\hline MF05-07_M13F-B12 & $\operatorname{PA}(2), \mathrm{FL}(1), \mathrm{HX}(2)$ & cytosolic cyclophilin 1 [Botryotinia fuckeliana] & AAQ16573 & $1.37 \mathrm{E}-60$ \\
\hline MF11-11_M13F-G08 & $\mathrm{PA}(1), \mathrm{FL}(1)$ & septin [Aspergillus fumigatus] & XP_748972 & $1.95 \mathrm{E}-113$ \\
\hline MF05-01_M13F-F08 & $\mathrm{FL}(2)$ & histidine kinase [Cochliobolus heterostrophus] & BAD07400 & $3.89 \mathrm{E}-31$ \\
\hline
\end{tabular}

${ }^{a}$ The number in the parenthesis indicates the count of ESTs with the homolog identified in the library.

transport, response to oxidative stress, hydrolytic enzymes, and signal cascade components. Three of four genes related to infection structures were identified from the PA library, while a putative homolog of hard surface induced protein was identified from the HX library. Genes involved in detoxification were discovered mainly from the FL library. Genes involved in oxidative stress responses were similarly expressed under all three conditions. Several ESTs showed sequence similarities to the genes for avirulence effectors, such as the Avr4, ecp2 and pSI-7 proteins of Cladosporium fulvum and the Protein SnodProtl precursor of Phaeosphaeria nodorum.

\section{Comparison of the EST Set to Sequenced Genomes of 18 Fungi}

We downloaded the assembled sequences and the predicted transcripts (or proteins) of 18 fungal genomes that have been sequenced through the Fungal Genome Initiative at the Broad Institute and Eukaryotic Genomics at the DOE Joint Genome Institute (JGI). The 1945 M. fijiensis unisequences were qerried against these genome sequence databases using the BLASTX program. The results are summarized in Table 5. In general, the relative overall level of homology between the unisequence set and a genome reflected the phylogenic relationship of $M$. fijiensis to the species analyzed. The highest numbers of unisequences matched to the transcripts derived from $M$. fijiensis, followed by a close relative species $M$. graminicola and other ascomycetous fungi (Table 5). They include both plant-pathogenic fungi (F. graminearum, M. grisea, M. fijiensis, M. graminicola, Nectria haematococca, and Stagonospora nodorum) and saphrophytic fungi (Aspergillus nidulans and N. crassa). Less unisequences matched to the predicted transcripts derived from the fungal species belonging to the phyla Basidiomycota and Zygomycota. The M. fijiensis unisequence set had the least homology to the genome of Batra- chochytrium dendrobatidis, a chytridiomycete fungus. In this case only $36 \%$ of the unisequences had a homolog with an E-value $<1 \mathrm{e}-05$.

To further evaluate the usefulness of the ESTs for annotation of the M. fijiensis genome, we performed a global BLAST analysis using the 3,771 ESTs against the assembled genome sequence (version 1.0) released on August 20, 2007. The draft includes a total of 10,327 gene models predicted and functionally annotated with the JGI annotation pipeline. Of the 3,771 ESTs from the three M. fijiensis cDNA libraries, 2,110 (55.6\%) had an almost $100 \%$ sequence identity (perfect E-value (0)) to the predicted transcripts, suggesting an accurate prediction of genes as well as gene structure. Further, 395 ESTs $(10.5 \%)$ exhibited significant $(0<$ E-value $1 \mathrm{e}<05)$ similarity to the predicted transcripts, suggesting an accurate gene prediction, but an inaccurate prediction of gene structure. However, some of the EST sequences might have intrinsic problems, such as unclean sequences, chimeric sequences, or unknown origins. It is noteworthy that 1,327 ESTs (34\%) had no similarity (no hits) to the predicted transcripts.

These 1,327 ESTs were further compared with the 382 scaffolds representing the draft whole genome sequence of M. fijiensis in order to identity their origin. BLASTN analysis identified an additional $337(9 \%)$ of 1,327 ESTs that showed $\sim 100 \%$ sequence identify to the genomic sequences in the 382 scaffolds. Another 519 (13\%) ESTs had a significant $(0<$ E-value $<1 \mathrm{e}-5)$ similarity to the genome sequence, inferring the presence of an intron, or introns, within the genes or DNA polymorphism between the different isolates used. In conclusion, the additional 856 (22\%) ESTs showed a sequence identity to the genomic sequences, but not to the predicted transcript sequences. This suggests that the gene prediction algorithms used for the M. fijiensis draft version did not recognize these regions as genes. Finally, $473(12 \%)$ of the ESTs did not show significant similarity to any ge- 
Table 5. Comparison of M. fijiensis Unisequeces to the Fully Sequenced Genomes of Fungi

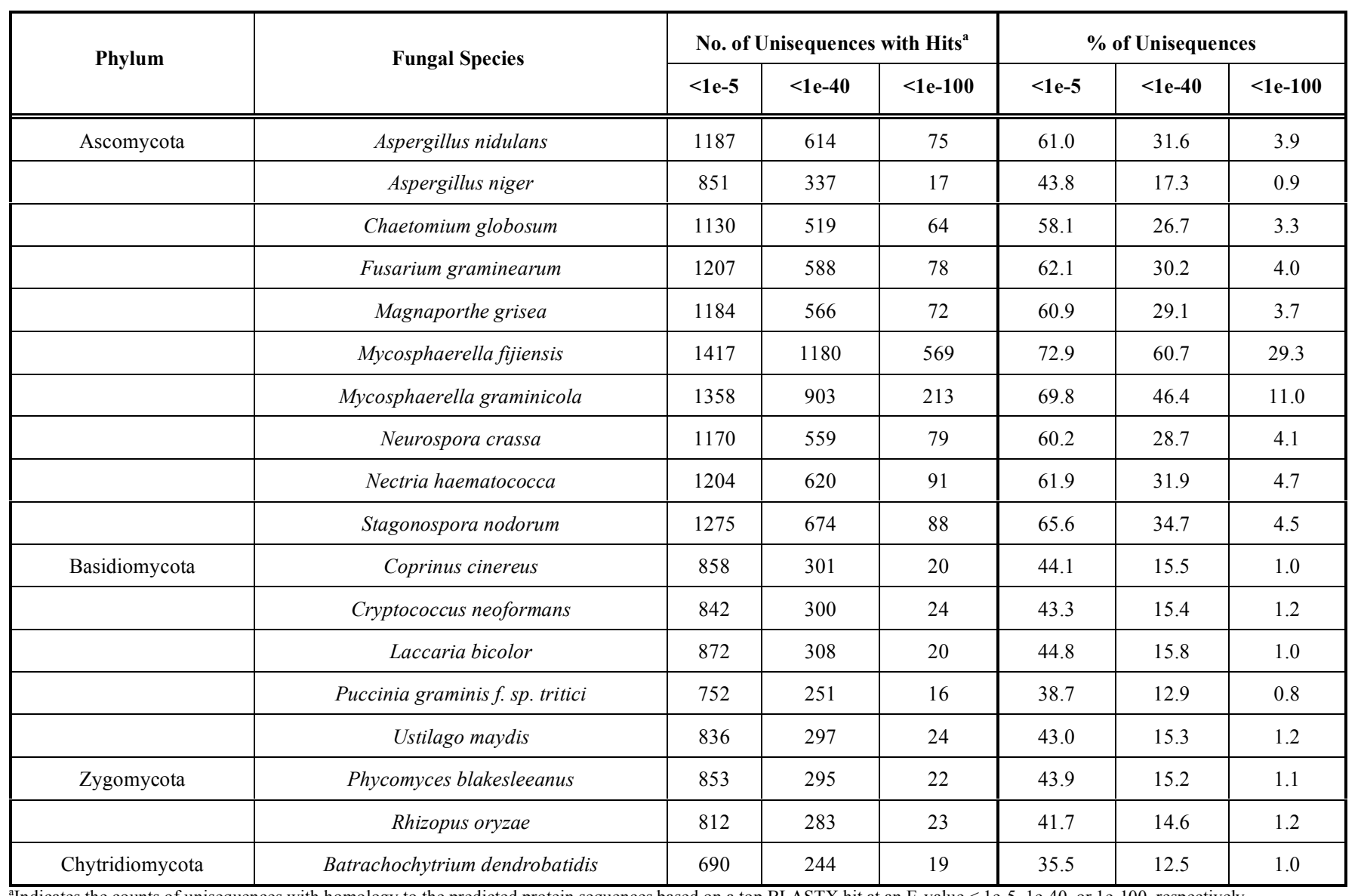

${ }^{a}$ Indicates the counts of unisequences with homology to the predicted protein sequences based on a top BLASTX hit at an E-value $<1 \mathrm{e}-5$, 1e-40, or 1e-100, respectively.

nome sequences. These EST sequences were clean, with an average length of $852 \mathrm{bp}$, and thus possibly derived from regions of the genome yet to be sequenced. These EST sequences could add value to the gene discovery process, complementing the whole genome sequencing effort.

\section{DISCUSSION}

The purpose of this study was to discover the genes expressed by $M$. fijiensis under three different environmental conditions, with special interest in candidate genes involved in pathogenicity. We chose to use pure fungal cultures in order to increase fungal gene discovery rates without complication from host ESTs [34, 35]. We determined 3,771 EST sequences from three cDNA libraries and assembled them into 1,945 putative genes. The estimated genome size of $M$. fijiensis is about $35 \mathrm{Mb}$ with a chromosome number of 17 or 18 (Andy James, personal communication). This genome size is within the range of other ascomycete fungi. It would be expected to contain around 8,000-9,000 genes [36], close to the 10,327 genes by ab intio gene prediction of the initial genome assembly (http://genome.jgi-psf.org/Mycfi1/Mycfil.home.html). Based on this estimation, the 1,945 unigenes identified represent $c a$. $20 \%$ of the genome in M. fijiensis. Overall, the sequences identified in this study present the first large-scale EST analysis of this fungus. This work provides an awareness of the biological processes that occur during growth on a solid medium, in Fries liquid medium, and in the presence of banana plant extracts and these processes may be related to the interaction between $M$. fijiensis and its banana host.
BLASTN comparisons of the 3,771 ESTs against the predicted transcripts identified 2,110 (55\%) with perfect, 395 (10\%) with partial, and 1,327 (35\%) with no matching partners. Among the 1,327 no-matching ESTs, 856 (22\%) had a significant sequence identity to the genomic sequences. Of these, $337(9 \%)$ had an almost 100\% identical match to the genomic sequence. This result suggests that the gene prediction was fairly accurate, though it missed about $20 \%$ of the ESTs, and that the prediction of gene structure was even less accurate than the prediction of genes. When a large number of gene sequences are not available, $a b$ initio gene prediction using diverse programs are employed to predict splicing probabilities of donor and acceptor sites, the coding probability of each single exon, and the probabilities of various gene models. The prediction of gene and gene structure can be significantly improved by adding more gene sequences, including ESTs, into the program training set (reviewed in [37]). The 3,771 ESTs reported in this study will be useful for improved prediction of gene structure as well as discovery of new genes in the draft genome.

Among the 45 contigs formed by more than 10 ESTs, 14 have unknown functions, indicating that these genes may be unique to $M$. fijiensis. Seven of the 45 contigs are ribosomal synthesis genes. High-level expression of ribosomal genes has been reported in several other phytopathogenic fungi, including Heterobasidion annosum [21], Ustilago maydis [25], and Gibberella zeae [20]. This may reflect the active growth of the fungus under the investigated conditions. In 
contrast, ribosomal proteins were expressed at a low levels in a closely related species, $M$. graminicola [23]. These contradictory results might have occurred because of different culture conditions for fungal tissues that have been used as library sources. Among the highly expressed genes, glucose repressible genes (contig 519, 546, and 560) were highly expressed in the HX library, while Opsin and opsin-like protein were highly expressed in the PA library. This is probably due to the continuous lighting conditions used during incubation as opposed to the dark mycelial growth conditions used for the other two libraries. Opsin is a light responsive protein and its expression can be induced by light [38]. Cation transport-related protein was also abundant in both the FL and HX libraries derived from liquid cultures. This may reflect that the uptake of cations from Fries medium is active in fungal mycelia.

Our interpretation of ESTs is based on the sequence similarity to other genes with known functions listed in public databases. Most putative pathogenicity genes occurred in the FL library compared to the other libraries in this study. Not surprisingly, several hydrolytic enzyme genes were identified in the FL library. There is substantial evidence supporting the importance of enzymatic digestion in host cuticle penetration and subsequent colonization. Several cell wall degrading enzyme (CWDE) coding genes and their control element genes have been identified as virulence factors and their null mutation has significantly reduced the infectivity of several diverse phytopathogens [39-43].

Typically, both the pathogenic fungus and its compatible host plant secrete large numbers of hydrolytic enzymes during fungus-host plant interactions. However, it is difficult to establish the role of individual hydrolytic enzymes in pathogenesis due to functional redundancy among numerous enzymes and multiple isozymes [42, 44, 45]. This enzymatic warfare between the plant and fungus is likely to produce signaling molecules, such as oligosaccharides, from the cell walls of the plant. Further, the fungus may activate additional defense and pathogenesis responses from the host. One of the responses to the enzyme warfare is an oxidative burst. Several genes that respond to or create oxidative stress were identified in this study. These genes include catalases, peroxidases, superoxide dismutases, monooxygenase, and cytochrome elements (Table 4). There is no supporting evidence yet, however, that any of these genes are directly associated with pathogenicity. In addition, only three hydrolytic enzymes were identified in this study, in contrast to general expectation, especially from the HX library that was prepared with mycelia grown in the presence of host extracts. The extracts might be insufficient elicitors compared to host cell wall components, which may be required for the full induction of putative CWDE gene expression demonstrated in other pathogenic fungi [46-48]. In general, it may be desirable to sequence further ESTs from libraries representing compatible host plant infection stages in order to better understand pathogen-host interactions.

We identified three genes for fungal toxin synthesis and ten genes for detoxification, drug resistance and transport protein (Table 4). Phytopathogenic fungi have to cope with many natural toxic compounds such as those produced by host plants during pathogenesis. Membrane proteins are known to provide protection against a wide range of natural toxic compounds by pumping them out of the cell $[49,50]$. An example of a transmembrane protein is MSF transporter whose activity is driven by the proton-motive force through membranes [51]. They are involved in protection against exogenous toxic compounds in case of Candida albicans [52] and S. cerevisiae [53]. One potential mechanism of infection is killing host cells with fungal phytotoxic secondary metabolites and toxic proteins. Transporters are known to mediate the secretion of endogenously produced toxins, such as aflatoxin, cercosporin, HC-toxin [54, 55]. For example, ToxA encodes an HC-toxin efflux pump which contributes to self-protection against HC-toxin in Cochliobolus carbonum. Like HTS1 encoding the central enzyme in HC-toxin biosynthesis, ToxA occurs only in isolates of the fungus that make HC-toxin. It is logical to consider that fungal transporters are important virulence factors, in parallel with secondary metabolites. Regardless, the function of transporters is to pump out the secondary metabolites originating from the pathogen itself or from the host plant. The necrotrophic fungus, Alternaria alternata, is known for its production of speciesspecific toxins encoded by nonribosomal polypeptide synthetases (NRPS) and polyketide synthases (PKS) [56]. Neither NRPS nor PKS have been identified in this study, in contrast to several transporters. This is probably due to their low level of expression under our trial conditions and the small numbers of EST collections from each library.

One clone in the FL library showed similarity to a signal transduction gene encoding a 'PMK1 homolog' from many pathogenic fungi. This MAP kinase and its homologs are essential for pathogenicity in many plant-pathogenic fungi $[57,58]$. MAP kinase is required for appressorium formation in fungal pathogens, such as Colletotrichum lagenarium, $M$. grisea, Cochliobolus heterostrophus, and Pyrenophora teres [59-62]. M. grisea and C. lagenarium produce especially large and heavily melanized appressoria that generate strong turgor pressure [63]. In both fungi, MAP kinase (Fus3/Kss 1 homolog) mutants are defective in appressorium formation and are nonpathogenic as a result of their inability to penetrate the plant epidermis and colonize host plant tissues [61, 62]. MAP kinase was also found to be required for full pathogenicity in the necrotrophic parasite Botrytis cinerea and in closely related Dothideomycete fungi, including Stagonospora nodorum, $P$. teres, C. heterostrophus, and Alternaria brassicicola [60-62, 64-67]. It is likely that the PMK1 homolog in M. fijiensis identified in this study also mediates plant infection either in the penetration and/or colonization stages. There are three additional kinases and one kinase regulatory subunit which may also be pathogenicity factors. These signal transduction pathways may be associated with the induction of downstream hydrolytic enzyme genes during pathogenicity as suggested previously [64].

Finally, we have identified ESTs encoding for proteins similar to several Avr factors, including AVR4 and ECP2 from Cladosporium fulvum. Both proteins are highly induced during host infection and were isolated from apoplastic washing fluids of tomato $[68,69]$. However, our EST analysis indicated that the AVR4 homolog was found in all three libraries (PA, FL, and HX) and the ECP 2 homolog existed in two of the libraries (FL and HX). It seems that these homologs are expressed in vitro although it is not known if their expression level is higher in vivo. It remains to be investigated whether these genes in $M$. fijiensis have similar 
functions to the Avr genes in C. fulvum. Targeted gene knockout study is the most straight-forward method to test the functions of these genes. Currently, targeted gene knockout methods for either targeted gene disruption or targeted gene deletion are unavailable for M. fijiensis. Successful transformation of exogenous DNA fragments, especially GFP expression vectors, has been reported [70]. Further optimization of the transformation method will lead to successful targeted gene knockout methods. Similarly, pathogenicity test methods [71] may be further optimized and established for M. fijiensis in order to discover pathogenicity genes and advance our understanding of their modes of action.

\section{CONCLUSION}

The putative identity of the mRNA transcripts discovered in three EST libraries led to several candidate genes potentially important in determining the outcome of a compatible fungal-plant interaction. Further functional analysis of the genes identified in this study by targeted gene replacement or disruption studies, as well as gene expression profiling experiments, will provide more information on the interaction between $M$. fijiensis and its economically important host, banana. Fungal ESTs identified in this study will also facilitate the annotation of the $M$. fijiensis genome sequence. A genome sequencing project was funded by the Department of Energy (DOE) in 2005. It was initiated at the DOE-Joint Genome Institute to generate a draft whole genome sequence. The ESTs identified in this study would aid annotation, and most specifically the prediction, of genes in the Mycosphaerella genome. Comparative analysis of ESTs with the closely related fungus $M$. graminicola and other distantly related fungi, may facilitate the identification of candidate pathogenicity genes and improve our understanding of the evolution of fungal plant pathogens. This could lead to development of more effective systems for banana disease control.

\section{ACKNOWLEDGEMENTS}

Financial support for this study was provided by University of Hawaii at Manoa to YC and SZ and North Dakota State University to SZ. We thank Scot C. Nelson for collecting $M$. fijiensis-infected banana leaves for fungal isolation and Baojun Yang for assistance in construction of cDNA libraries, and Fred Brooks for helpful discussion. We would also like to thank Zheng Jin Tu at the University of Minnesota and Anupma Sharma at UHM for their assistance with various computational aspects of this study.

\section{ABBREVIATIONS}

\section{$\mathrm{EST}=$ Expressed Sequence Tags}

$\mathrm{PA}=\mathrm{cDNA}$ library representing MF11-Hilo grown on PDA for 4 weeks

$\mathrm{FL}=$ cDNA library representing MF5-Hilo grown in Fries liquid medium for 4 days

$\mathrm{HX}=$ cDNA library representing MF5-Hilo grown in Fries liquid medium plus banana leaf extract

\section{REFERENCES}

[1] Ploetz RC. Black Sigatoka of Banana. The Plant Health Instructor [serial on the internet] 2001; [cited on 2008 June 1] Available from: http://www.apsnet.org/education/feature/banana/

[2] Mobambu KN, Gauhl F, Vuylsteke D, Ortiz R, Pasberg-Gauhl C, WSwennen R. Yield loss in plantain from blacks Sigatoka leaf spot and field performance of resistant hybrids. Field Crops Res 1993; 35: 35-42.

[3] Gauhl F. Epidemiology and ecology of black Sigatoka (Mycosphaerella fijiensis Morlet) on plantain and banana (Musa spp.) in Costa Rica, Central America. Ph.D. dissertation, Universität Göttingen, 1994.

[4] Ploetz RC, Mourichon X. First report of black sigatoka in Florida. Plant Dis 1999; 83: 300 .

[5] Stansbury C, KMcKirdy S, Power G. Black Sigatoka disease: new technologies to strengthen eradication strategies in Australia. Aust Plant Pathol 2006; 35: 181-93.

[6] Chin KM, Wirz M, Laird D. Sensitivity of Mycosphaerella fijiensis from banana to trifloxystrobin. Plant Dis 2001; 85: 1264-70.

[7] Romero R, Sutton T. Characterization of benomyl resistance in Mycosphaerella fijiensis, cause of black Sigatoka of banana, in Costa Rica. Plant Dis 1998; 82: 931-4.

[8] Romero RA, Sutton TB. Sensitivity of Mycosphaerella fijiensis, causal agent of black Sigatoka of banana, to propiconazole. Phytopathology 1997; 87: 96-100.

[9] Castillo LE, Ruepert C, Solis E. Pesticide residues in the aquatic environment of banana plantation areas in the north Atlantic zone of Costa Rica. Environ Toxicol Chem 2000; 9: 1942-50.

[10] Chaves A, Shea D, Cope WG. Environmental fate of chlorothalonil in a Costa Rican banana plantation. Chemosphere 2007; 69: 116674.

[11] Daly GL, Lei YD, Teixeira C, Muir DCG, Castillo LE, Wania F. Accumulation of current-use pesticides in neotropical montane forests. Environ Sci Technol 2007; 41: 1118-23.

[12] Vindas R, Ortiz F, Ramírez V, Cuenca P. Genotoxicity of three pesticides used in Costa Rican banana plantations. Rev Biol Trop 2004; 52: 601-9.

[13] Janick J. Fruit breeding in the 21st century. In: Galan Sauco V, Ed. Proceedings of the First International Symposium on Banana in the Subtropics; 1997: Tenerife, Spain; 1998; pp. 39-46.

[14] Simmonds NW. Bananas. London: Longmans; 1966.

[15] Simmonds NW, Shepherd K. Taxanomy and origins of cultivated bananas. J Linn Soc Bot 1955; 55: 302-12.

[16] Persley GJ, George P, Eds. Banana Improvement: Research challenges and opportunities. Washington D.C: The World Bank; 1996.

[17] Persley GJ, George P, Eds. Banana, Breeding, and Biotechnology: Commodity advances through banana improvement project research, 1994-1998. Washington D.C: The World Bank; 1999.

[18] Bakry F, Carreel F, Caruana ML, et al. Banana. In: Charrier A, Jacquot M, Hamon S, Nicolas D, Eds. Tropical plant breeding. Centre de cooperation internationale en researche agronomique pour le developpement (CIRAD): France; 2001; 1-29.

[19] Fullerton RA, Olsen TL. Pathogenic variability in Mycosphaerella fijiensis MORELET, cause of black Sigatoka in banana and plantain. NZ J Crop Hortic Sci 1995; 23: 39-48.

[20] Trail F, Xu JR, San Miguel P, Halgren RG, Kistler HC. Analysis of expressed sequence tags from Gibberella zeae (anamorph Fusarium graminearum). Fungal Genet Biol 2003; 38: 187-97.

[21] Abu SM, Li G, Asiegbu FO. Identification of Heterobasidion annosum (S-type) genes expressed during initial stages of conidiospore germination and under varying culture conditions. FEMS Microbiol Lett 2004; 233: 205-13.

[22] Ebbole DJ, Jin Y, Thon M, et al. Gene discovery and gene expression in the rice blast fungus, Magnaporthe grisea: analysis of expressed sequence tags. Mol Plant Microbe Interact 2004; 17: 133747.

[23] Keon J, Antoniw J, Rudd J, Skinner W, Hargreaves J, HammondKosack K. Analysis of expressed sequence tags from the wheat leaf blotch pathogen Mycosphaerella graminicola (anamorph Septoria tritici). Fungal Genet Biol 2005; 42: 376-89. 
[24] Zhu H, Nowrousian M, Kupfer D, et al. Analysis of expressed sequence tags from two starvation, time-of-day-specific libraries of Neurospora crassa reveals novel clock-controlled genes. Genetics 2001; 157: 1057-65.

[25] Nugent KG, Choffe K, Saville BJ. Gene expression during Ustilago maydis diploid filamentous growth: EST library creation and analyses. Fungal Genet Biol 2004; 41: 349-60.

[26] Stover RH. Distribution and cultural characteristics of the pathogens causing banana leaf spot. Trop Agric (Trinidad) 1976; 53: $111-4$

[27] Johanson A, Jeger MJ. Use of PCR for detection of $M y$ cosphaerella fijiensis and M. musicola, the causal agents of Sigatoka leaf spots on banana and plantain. Mycol Res 1993; 97: 670-4.

[28] Ewing B, Hillier L, Wendl MC, Green P. Base-calling of automated sequencer traces using phred. I. Accuracy assessment. Genome Res 1998; 8: 175-85.

[29] Altschul SF, Madden TL, Schaffer AA, et al. Gapped BLAST and PSI-BLAST: a new generation of protein database search programs. Nucleic Acids Res 1997; 25: 3389-402.

[30] Mewes HW, Frishman D, Guldener U, et al. MIPS: a database for genomes and protein sequences. Nucleic Acids Res 2002; 30: 31-4.

[31] Cramer RA, Lawrence CB. Identification of Alternaria brassicicola genes expressed in planta during pathogenesis of Arabidopsis thaliana. Fungal Genet Biol 2004; 41: 115-28.

[32] Diatchenko L, Lau YF, Campbell AP, et al. Suppression subtractive hybridization: a method for generating differentially regulated or tissue-specific cDNA probes and libraries. Proc Natl Acad Sci USA 1996; 93: 6025-30.

[33] Soanes DM, Skinner W, Keon J, Hargreaves J, Talbot NJ. Genomics of phytopathogenic fungi and the development of bioinformatic resources. Mol Plant Microbe Interact 2002; 15: 421-7.

[34] Talbot N, McCafferty H, Ma M, Moore K, Hamer J. Nitrogen starvation of the rice blast fungus Magnaporthe grisea may act as an environmental cue for disease symptom development. Physiol Mol Plant Pathol 1997; 50: 179-95.

[35] Cramer RA, La Rota CM, Cho Y, et al. Bioinformatic analysis of expressed sequence tags derived from a compatible Alternaria brassicicola-Brassica oleracea interaction. Mol Plant Pathol 2006; 7: 113-24.

[36] Kupfer DM, Reece CA, Clifton SW, Roe BA, Prade RA. Multicellular ascomycetous fungal genomes contain more than 8000 genes. Fungal Genet Biol 1997; 21: 364-72.

[37] Cho Y, Walbot V. Computational methods for gene annotation: the Arabidopsis genome. Curr Opin Biotechnol 2001; 12: 126-30.

[38] Purschwitz J, Muller S, Kastner C, Fischer R. Seeing the rainbow: light sensing in fungi. Curr Opin Microbiol 2006; 9: 566-71.

[39] Ospina-Giraldo MD, Mullins E, Kang S. Loss of function of the Fusarium oxysporum SNF1 gene reduces virulence on cabbage and Arabidopsis. Curr Genet 2003; 44: 49-57.

[40] Shieh MT, Brown RL, Whitehead MP, et al. Molecular genetic evidence for the involvement of a specific polygalacturonase, $P 2 c$, in the invasion and spread of Aspergillus flavus in cotton bolls. Appl Environ Microbiol 1997; 63: 3548-52.

[41] ten Have A, Mulder W, Visser J, van Kan JA. The endopolygalacturonase gene Bcpgl is required for full virulence of Botrytis cinerea. Mol Plant Microbe Interact 1998; 11: 1009-16.

[42] Tonukari NJ, Scott-Craig JS, Walton JD. The Cochliobolus carbonum $S N F 1$ gene is required for cell wall-degrading enzyme expression and virulence on maize. Plant Cell 2000; 12: 237-48.

[43] Voigt CA, Schafer W, Salomon S. A secreted lipase of Fusarium graminearum is a virulence factor required for infection of cereals. Plant J 2005; 42: 364-75.

[44] Mendgen K, Hahn M, Deising H. Morphogenesis and mechanisms of penetration by plant pathogenic fungi. Annu Rev Phytopathol 1996; 34: 367-86.

[45] Walton JD. Deconstructing the cell wall. Plant Physiol 1994; 104: 1113-8.
[46] Mendoza-Mendoza A, Pozo MJ, Grzegorski D, et al. Enhanced biocontrol activity of Trichoderma through inactivation of a mitogen-activated protein kinase. Proc Natl Acad Sci USA 2003; 100: 15965-70.

[47] Olmedo-Monfil V, Mendoza-Mendoza A, Gomez I, Cortes C, Herrera-Estrella A. Multiple environmental signals determine the transcriptional activation of the mycoparasitism related gene $p r b 1$ in Trichoderma atroviride. Mol Genet Genomics 2002; 267: 703-12.

[48] Rogers LM, Kim YK, Guo W, Gonzalez-Candelas L, Li D, Kolattukudy PE. Requirement for either a host- or pectin-induced pectate lyase for infection of Pisum sativum by Nectria hematococca. Proc Natl Acad Sci USA 2000; 97: 9813-8.

[49] Andrade AC, Van Nistelrooy JG, Peery RB, Skatrud PL, De Waard $\mathrm{MA}$. The role of $\mathrm{ABC}$ transporters from Aspergillus nidulans in protection against cytotoxic agents and in antibiotic production. Mol Gen Genet 2000; 263: 966-77.

[50] Del Sorbo G, Schoonbeek H, De Waard MA. Fungal transporters involved in efflux of natural toxic compounds and fungicides. Fungal Genet Biol 2000; 30: 1-15.

[51] Pao SS, Paulsen IT, Saier MH, Jr. Major facilitator superfamily. Microbiol Mol Biol Rev 1998; 62: 1-34.

[52] Calabrese D, Bille J, Sanglard D. A novel multidrug efflux transporter gene of the major facilitator superfamily from Candida albicans (FLU1) conferring resistance to fluconazole. Microbiology 2000; 146: 2743-54.

[53] Alarco AM, Balan I, Talibi D, Mainville N, Raymond M. AP1mediated multidrug resistance in Saccharomyces cerevisiae requires FLR1 encoding a transporter of the major facilitator superfamily. J Biol Chem 1997; 272: 19304-13.

[54] Pitkin JW, Panaccione DG, Walton JD. A putative cyclic peptide efflux pump encoded by the TOXA gene of the plant-pathogenic fungus Cochliobolus carbonum. Microbiology 1996; 142: 1557-65.

[55] Paulsen IT, Brown MH, Skurray RA. Proton-dependent multidrug efflux systems. Microbiol Rev 1996; 60: 575-608

[56] Ito K, Tanaka T, Hatta R, Yamamoto M, Akimitsu K, Tsuge T. Dissection of the host range of the fungal plant pathogen Alternaria alternata by modification of secondary metabolism. Mol Microbiol 2004; 52: 399-411.

[57] Xu JR. Map kinases in fungal pathogens. Fungal Genet Biol 2000; 31: $137-52$

[58] Zhao X, Mehrabi R, Xu JR. Mitogen-activated protein kinase pathways and fungal pathogenesis. Eukaryot Cell 2007; 6: 1701-14.

[59] Lev S, Sharon A, Hadar R, Ma H, Horwitz BA. A mitogenactivated protein kinase of the corn leaf pathogen Cochliobolus heterostrophus is involved in conidiation, appressorium formation, and pathogenicity: diverse roles for mitogen-activated protein kinase homologs in foliar pathogens. Proc Natl Acad Sci USA 1999; 96: 13542-7.

[60] Ruiz-Roldan MC, Maier FJ, Schafer W. PTK1, a mitogenactivated-protein kinase gene, is required for conidiation, appressorium formation, and pathogenicity of Pyrenophora teres on barley. Mol Plant Microbe Interact 2001; 14: 116-25.

[61] Takano Y, Kikuchi T, Kubo Y, Hamer JE, Mise K, Furusawa I. The Colletotrichum lagenarium MAP kinase gene $C M K 1$ regulates diverse aspects of fungal pathogenesis. Mol Plant Microbe Interact 2000; 13: 374-83.

[62] Xu JR, Hamer JE. MAP kinase and cAMP signaling regulate infection structure formation and pathogenic growth in the rice blast fungus Magnaporthe grisea. Genes Dev 1996; 10: 2696-706.

[63] Thines E, Weber RW, Talbot NJ. MAP kinase and protein kinase A-dependent mobilization of triacylglycerol and glycogen during appressorium turgor generation by Magnaporthe grisea. Plant Cell 2000; 12: 1703-18.

[64] Cho Y, Cramer RA Jr, Kim KH, et al. The Fus3/Kss1 MAP kinase homolog Amkl regulates the expression of genes encoding hydrolytic enzymes in Alternaria brassicicola. Fungal Genet Biol 2007; 44: $543-53$. 
[65] Di Pietro A, Garcia-MacEira FI, Meglecz E, Roncero MI. A MAP kinase of the vascular wilt fungus Fusarium oxysporum is essential for root penetration and pathogenesis. Mol Microbiol 2001; 39: $1140-52$.

[66] Mey G, Held K, Scheffer J, Tenberge KB, Tudzynski P. CPMK2, an SLT2-homologous mitogen-activated protein (MAP) kinase, is essential for pathogenesis of Claviceps purpurea on rye: evidence for a second conserved pathogenesis-related MAP kinase cascade in phytopathogenic fungi. Mol Microbiol 2002; 46: 305-18.

[67] Zheng L, Campbell M, Murphy J, Lam S, Xu JR. The BMP1 gene is essential for pathogenicity in the gray mold fungus Botrytis cinerea. Mol Plant Microbe Interact 2000; 13: 724-32.

[68] Joosten MHAJ, Vogelsang R, Cozijnsen TJ, Verberne MC, De Wit PJGM. The biotrophic fungus Cladosporium fulvum circumvents
Cf-4-mediated resistance by producing unstable AVR4 elicitors. Plant Cell 1997; 9: 367-379.

[69] Van den Ackerveken GFJM, Van Kan JAL, Joosten MHAJ, Muisers JM, Verbakel HM, De Wit PJGM. Characterization of two putative pathogenicity genes of the fungal tomato pathogen Cladosporium fulvum. Mol Plant Microbe Interact 1993, 6: 210-15.

[70] Balint-Kurti PJ, May GD, Churchill AC. Development of a transformation system for Mycosphaerella pathogens of banana: a tool for the study of host/pathogen interactions. FEMS Microbiol Lett 2001; 195: 9-15.

[71] Donzelli B, Churchill A. A quantitative assay using mycelial fragments to assess virulence of Mycosphaerella fijiensis. Phytopathology 2007; 97: 916-29.

(C) Cho et al:; Licensee Bentham Open.

This is an open access article licensed under the terms of the Creative Commons Attribution Non-Commercial License (http://creativecommons.org/licenses/by$\mathrm{nc} / 3.0 /$ ) which permits unrestricted, non-commercial use, distribution and reproduction in any medium, provided the work is properly cited. 